\title{
Plasma Debinding and Sintering of Metal Injection Moulded 17-4PH Stainless Steel
}

\author{
Renan Schroeder*, Gisele Hammes, Cristiano Binder, Aloisio Nelmo Klein \\ Materials Laboratory - LabMat, Mechanical Engineering Department - EMC, \\ Federal University of Santa Catarina - UFSC, CEP 88040-900, Florianópolis, SC, Brazil
}

Received: July 11, 2011; Revised: October 4, 2011

\begin{abstract}
In this work, 17-4PH stainless steel parts processed in a Plasma Assisted Debinding and Sintering (PADS) furnace were characterised in terms of microstructure, final density, microhardness, carbon content and tensile behaviour. To determine whether these properties were satisfactory, the same characterisation procedure was conducted on the parts processed by conventional batch furnaces that are normally employed in Metal Injection Moulding industrial plants. The properties were in good agreement, and only slight differences like an extremely low carbon content $(0.003 \%$ w/o) were observed. It has been seen that not only economical advances but also intricate materials with suitable responses may be obtained using PADS.
\end{abstract}

Keywords: plasma assisted debinding and sintering, 17-4PH stainless steel, processing lead-time reduction

\section{Introduction}

Metal Injection Moulding (MIM) has been established as a mass production process all over the world because of the possibility of the production of near-net-shape and high performance materials with complex geometries. Despite the increasing growth observed over the past two decades, advances aiming for new materials and cost-effective processes are still necessary. Certainly one of the keys for reducing costs in MIM is improving the expensive debinding and sintering step. It is well known that these advances will lead to more intelligent control systems and cutting-edge technologies.

A new process called Plasma Assisted Debinding and Sintering (PADS) was developed by Klein et al. ${ }^{1}$, which performs clean and quick debinding and sintering of MIM parts. In this route the high reactivity of the plasma environment in an abnormal glow discharge, created by a DC electrical discharge generated between two electrodes placed in a low pressure gas environment ( 0.1 to 15 Torr, 13 to $2000 \mathrm{~Pa}$ ), is used for dissociation of the binders macromolecules. Process takes less time for thermal debinding and sintering, both achieved in the same equipment and same thermal cycle, avoiding the condensation of organic residues in the processing environment. Some papers have already reported on the PADS equipment ${ }^{2}$ and industrial MIM applications ${ }^{3}$. Generally speaking, this promising technique has received much interest in MIM for the following significant changes:

- Cycle time: debinding takes place while the parts are ramping to the sintering temperature. Thus, only one holding at high temperature is necessary.

- Clean process: no organic residues are found in the cold regions of the furnace after the process. Thus, a cleaning procedure every cycle is not required, and the furnace is much more environmentally friendly than conventional equipment because the binders are broken down to low molecular weight gases like methane, ethane, and propane, which do not condense in the furnace chamber.

These improvements were possible because of the effects of the abnormal DC glow discharge generated over the green samples. The plasma details have been widely discussed in the patents ${ }^{1,4}$ and are not the focus of the current investigation. Although the plasma discharge properties are not discussed here, the PADS technology deserves some attention. In summary, the following steps occur during debinding:

- Ionized atoms bombard the cathode, generating electrons, heat and sputtering. Because this technology uses low energy plasma, both the heat and sputtering rate are irrelevant. Thus, the heat, generated from inelastic collisions, is not sufficient to heat up the furnace, and contamination from the sputtered material of the cathode does not occur. Therefore, the only species that are important for debinding are the electrons.

- The electrons from the cathode are accelerated towards the anode. Because the green samples are set in the floating potential between cathode-anode, these electrons collide against the organic macromolecules of binders present on green part surface and in the processing environment (after evaporation).

- The energy of the electrons transferred to the organic macromolecules by inelastic collisions is high enough to split them into low carbon radicals $\left(\mathrm{C}_{\mathrm{x}} \mathrm{H}_{\mathrm{y}}\right)$.

- The free hydrogen atoms generated from the dissociation of the flowing hydrogen molecules introduced in the chamber $\left(\mathrm{e}+\mathrm{H}_{2}=\mathrm{H}+\mathrm{H}+\mathrm{e}\right)$ cap off the open carbon radicals, forming low molecular gases such as methane and ethane.

- These gases are easily purged from the chamber by a vacuum pump. As a consequence, the chamber remains clean.

The purpose of the current work is not to discuss the process variables, the furnace project proposed ${ }^{5}$ or any other topic related to the equipment, but to examine the plasma debound and sintered parts. Thereby, the main goal is to show that similar metallurgical properties obtained by the conventional route can be obtained in a shorter cycle-time with the plasma assisted route.

The material used for this investigation was the widely used MIM 17-4PH stainless steel. Its major application is in aerospace, food, petroleum, orthodontics and household parts. Zhang and German ${ }^{6}$ showed its very interesting combination of high mechanical and corrosion resistance, although it has completely different properties after any heat treatment. Therefore, the processing of $17-4 \mathrm{PH}$ stainless steel under plasma is a fairly interesting topic to research in depth. 


\section{Experimental Procedure}

The 17-4PH stainless steel powder was supplied by the MIM producer Lupatech/Steelinject. The main properties of this powder are tap density of $4.40 \mathrm{~g} . \mathrm{cm}^{-3}$ and an avg. particle size of d50:10.3 $\mu \mathrm{m}$. The powder was mixed with the following organic binders: paraffin wax, polypropylene, stearic acid (surfactant), ethylene vinyl acetate copolymer (EVA) and amide wax. The feedstock was prepared in a Haake Sigma mixer $\left(180{ }^{\circ} \mathrm{C}, 70 \mathrm{rpm}, 90\right.$ minutes.) and injection moulded in a one barrelled machine, Arburg 320S. The samples were moulded in the shape of tensile test specimens (Standard MPIF 35).

The debinding was carried out in a stepwise process. First, the waxes were chemically debound in a hexane bath at $60{ }^{\circ} \mathrm{C}$ for 1 hour. In this stage, an open pore network is formed, which allows the removal of the backbone polymer during the second debinding step. After that, the thermal extraction and sintering was conducted in two processing routes:

- Thermal debinding in a High Temperature Burnout (HTB) furnace, followed by sintering in a low vacuum furnace.

- Thermal debinding in a Plasma Assisted Debinding and Sintering (PADS) furnace in a single cycle.

One important difference between these routes is the working pressure in the chamber. The plasma furnace runs with a $\mathrm{H}_{2}-\mathrm{Ar}$ pressure level of 1 to $5 \mathrm{mbar}$, but the conventional vacuum furnace runs at approximately 130 to $150 \mathrm{mbar}$. The isothermal sintering was set up at $1330^{\circ} \mathrm{C}$ for 1 hour.

The sintered densities were evaluated by Archimedes's method. The carbon testing was conducted in a Leco WR-112 carburizing furnace. The microhardness was evaluated using a Shimadzu HMV 2000 microindentation testing system for Vickers measurements under a $0.2 \mathrm{~kg}$ load. Tensile tests were carried out with MTS (model 609) equipment. The X-ray diffraction (XRD) tests were conducted in a Philips X'pert with $\mathrm{Cu}-\mathrm{k} \alpha$ radiation.

A solution of marble was used to etch the surface of a crosssectioned 17-4PH sample. To identify metallurgical microstructures, the etched samples were observed in optical and scanning electron microscopes. A semi-quantitative analysis of the chemical composition was carried out via energy dispersive X-ray microanalysis (EDX) in the scanning electron microscope.

In each test conducted in this work, five samples in the as-sintered condition were analyzed under identical procedures to obtain the solid values.

\section{Materials Characterisation and Discussion}

Debinding and sintering of $17-4 \mathrm{PH}$ stainless steel parts in the plasma system was carried out for approximately 10 hours. In the conventional route (HTB + vacuum furnace), it took up to 50 hours, which demonstrates that the PADS system leads to a large reduction in the processing time and in the energy and gas consumption. This kind of achievement is desired by all MIM producers all over the world, and certainly such an advance may contribute to the continuous growth of the MIM business.

However, the processing time is not the only request for advances in debinding and sintering. The quality of sintered parts has to be assured to attain the engineering specifications. Based on the necessity of reliability, the following paragraphs show a characterisation of the plasma debound and sintered 17-4PH stainless steel parts compared to those subjected to the conventional MIM route.

Table 1 shows the average results from the carbon, density and microhardness tests carried out on samples processed in both the debinding and sintering systems.

The quality of the thermal debinding process can be evaluated by the carbon content of the sintered parts. If the carbon content
Table 1. Carbon content, density and microhardness of the sintered MIM 17-4PH stainless steel parts processed using both techniques studied.

\begin{tabular}{cccc}
\hline System & $\begin{array}{c}\text { Carbon content } \\
(\% \text { w/o })\end{array}$ & $\begin{array}{c}\text { Density } \\
\left({\left.\mathrm{g} . \mathrm{cm}^{-3}\right)}^{-3}\right.\end{array}$ & $\begin{array}{c}\text { Microhardness } \\
\text { HV 0.2 }\end{array}$ \\
\hline HTB + Vacuum & $0.014 \pm 0.004$ & $7.63 \pm 0.05$ & $290 \pm 15$ \\
PADS & $0.003 \pm 0.003$ & $7.68 \pm 0.05$ & $315 \pm 15$ \\
\hline
\end{tabular}

exceeds the initial one, the binder was not completely extracted. On the other hand, if the quantity is lower than the starting condition, a decarburization of the sintered parts has occurred. It is always important to keep in mind that reactive gases such as oxygen and hydrogen react easily with carbon, making carbon control one of the most complex operations in the MIM process.

The carbon tests conducted in this investigation revealed lower values of carbon for the parts processed under plasma $(0.003 \% \mathrm{w} / \mathrm{o})$ than for those processed using the conventional route $(0.014 \% \mathrm{w} / \mathrm{o})$. Both values were lower than the initial carbon content of the powder $(0.051 \% \mathrm{w} / \mathrm{o})$, which means that the binder extraction was complete in both systems, and a slight decarburization occurred, probably due to the reaction with oxygen present in the oxide layer covering the powder particles. The difference in carbon content between the parts processed in each system can be explained in the following scenarios:

- Conventional route: molecular hydrogen gas $\left(\mathrm{H}_{2}\right)$ flowing continuously inside the furnace chamber. A slight decarburization of the parts was observed, and it was probably driven by the oxide reaction instead of the hydrogen one.

- Plasma route: atomic hydrogen gas $(\mathrm{H})$ flowing in the cathodeanode shelves. These molecules are more reactive than $\mathrm{H}_{2}$ molecules, which might enhance the reactions with carbon. As a consequence, very low carbon levels were measured in comparison to those found using the conventional route.

Additionally, the low quantity of carbon observed in the parts processed using plasma opened up an interesting new discussion. A very low carbon content in stainless steel means a low probability of having Cr-rich carbides precipitate over the grain boundaries. It is well known that, when this phenomenon occurs, the areas that have lost $\mathrm{Cr}$ atoms to carbides are more susceptible to corrosive agents. This process is called the sensitization effect and has been discussed in depth by Jones and Randle ${ }^{7}$. Therefore, one could suggest that the plasma-sintered 17-4PH stainless steel has improved corrosion resistance. However, a systematic investigation on the corrosive properties of these materials is still necessary before any conclusion is drawn. Earlier studies have already shown that carbon has a noticeable effect on the density, microstructure, mechanical properties and corrosion resistance ${ }^{8}$.

The densities of the sintered tensile specimens were high for both sintering routes and were nearly identical. The values obtained demonstrate that these parts reached almost full density (approximately $97-98 \%$ of the theoretical density $-7.85 \mathrm{~g} . \mathrm{cm}^{-3}$ ). The slight difference in density between the cycles might be due to the carbon content and, consequently, the resulting microstructure. This relation is discussed further in terms of the microstructures of 17-4PH stainless steel.

The micro indentation tests did not reveal any considerable difference in hardness for the materials processed in each furnace, and the results were in agreement with those found in the literature. It may be interesting to point out that both the hardness and strength of 17-4PH stainless steel can be greatly enhanced by aging between 450 and $510{ }^{\circ} \mathrm{C}$ due to the precipitation of copper particles 9 . 
Figures 1a-b illustrate the microstructures of MIM 17-4PH sintered at $1330{ }^{\circ} \mathrm{C}$ in PADS and in a conventional low vacuum furnace. In both cases, the metallurgical constituents were basically martensite and delta ferrite. The presence of retained austenite may be considered. However, it is present in very low amounts that are nearly impossible to visualize by optical microscopy. These constituents were already discussed in the literature by Wu et al. ${ }^{8,10}$ in their two studies.

Formation of delta ferrite during the high temperature sintering process can be examined in the phase diagram of the $17-4 \mathrm{PH}$ stainless steel showed in Figure 2. According to this diagram, the microstructural evolution during sintering is summarized in the following scenarios:

- ferrite $\alpha$;

- austenite $\gamma$

- austenite $\gamma+$ ferrite $\delta$.

Furthermore, the phase diagram shows that the formation reaction of delta ferrite is strongly affected by the carbon content. Lower amounts of carbon increase the quantity of delta ferrite. Wu et al. ${ }^{8}$ and Sago et al. ${ }^{9}$ investigated the formation of delta ferrite during sintering at different temperatures and with different carbon contents. Both concluded that the sintering of $17-4 \mathrm{PH}$ stainless steel above

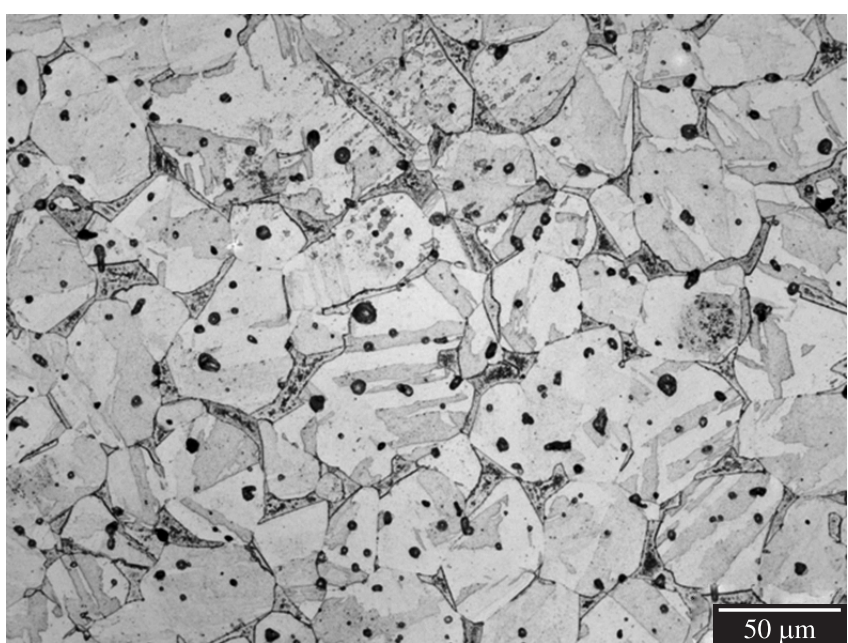

(a)

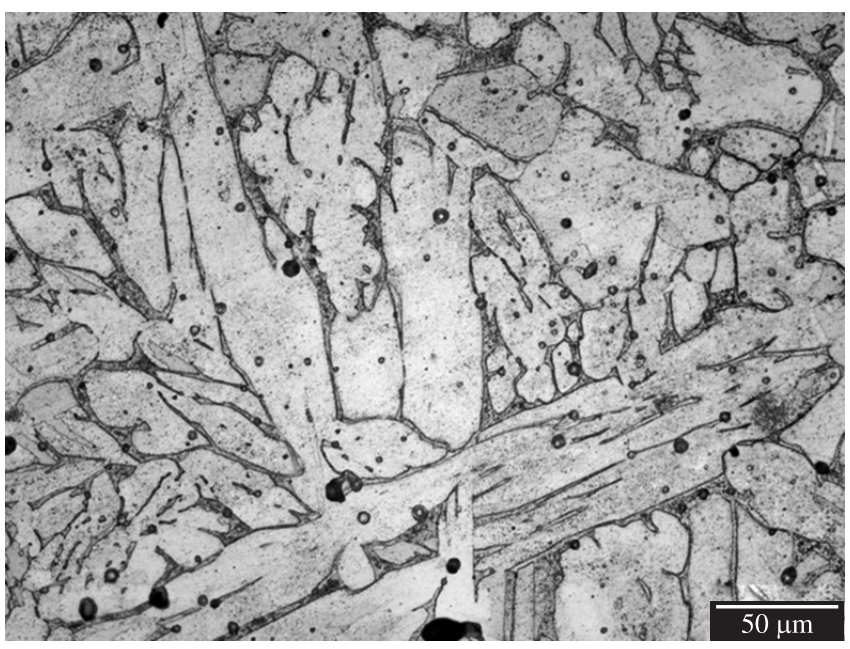

(b)

Figure 1. Micrographs of MIM 17-4PH stainless steel sintered at $1330{ }^{\circ} \mathrm{C}$ in: a) conventional vacuum furnace and b) PADS furnace. more or less $1220{ }^{\circ} \mathrm{C}$ leads to the formation of delta ferrite in a continuous grain boundary morphology. Other processing conditions involving the kinetics/thermodynamics of reactions may also affect the predictions of the stable phase diagram.

In the current investigation, the amounts of delta ferrite were higher for the parts processed in PADS than in a vacuum furnace, which is in agreement with the relation of carbon/delta ferrite contents postulated by Sago et al. ${ }^{9}$. Furthermore, it was concluded in these previous studies that more delta ferrite leads to higher density values. This behaviour was also found in the current investigation on 17-4PH stainless steel processing. The higher densities for lower carbon steels are linked to the enhancement of the densification rate due to higher amounts of delta ferrite. It is well known that the volume diffusion is faster in the bcc structure of ferrite than in the fcc structure of austenite.

To improve characterisation of the microstructural constituents, XRD tests were carried out. The spectra (Figure 3 ) obtained revealed an equivalence of peaks, which fits the typical data of the bcc crystal structure - Reference 00-001-1114 ${ }^{12}$. Thus, both steels could present ferritic structures in spite of the martensitic structures normally found for 17-4PH stainless steel. However, it is well known that the bcc ferrite has a crystal structure that is very similar to bct martensite, thus explaining the diffraction pattern. As demonstrated by microstructural analysis, the constituents are martensite + delta ferrite. The XRD tests did not show any peaks representing the fcc austenite, which means it was almost free or at least had very low levels of this phase.

Despite similar microstructural constituents found in the alloys, the shape form factor of these constituents under plasma was different than those sintered with the conventional route. An irregular grain growth was observed during the plasma processing of MIM 17-4PH stainless steel. The reasons for the grain growth are not very clear, although the following explanations are suggested.

\subsection{Copper evaporation}

Table 2 shows the copper content of the powder used and of the sintered parts. The copper level in the plasma processed parts was lower than that in the parts processed via the traditional route. Thus,

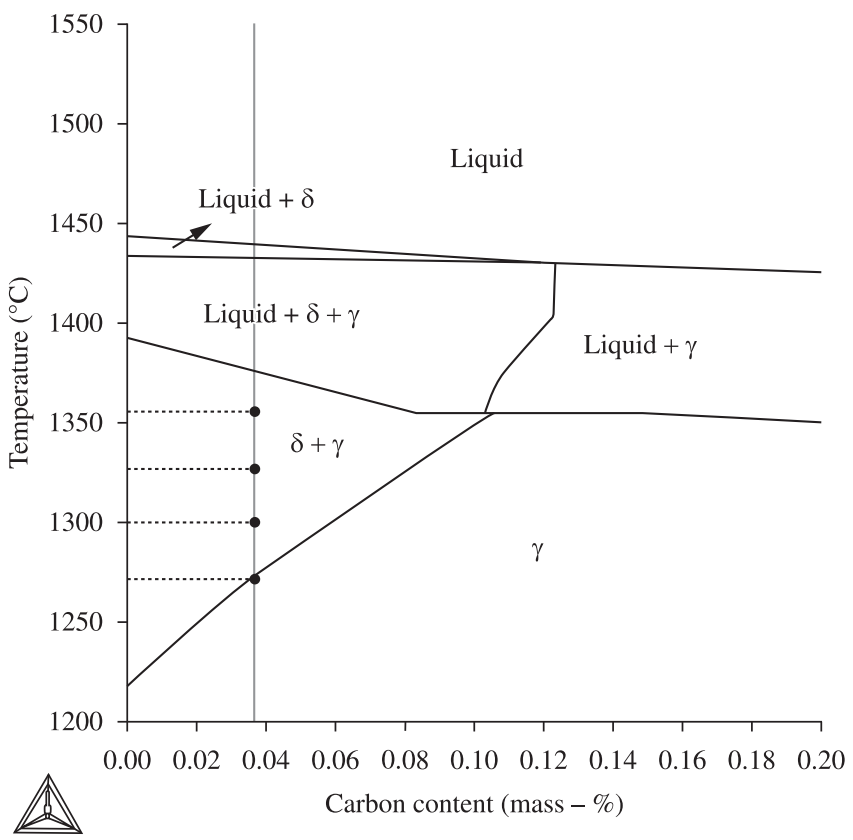

Figure 2. Phase diagram of 17-4PH alloy ${ }^{11}$. 


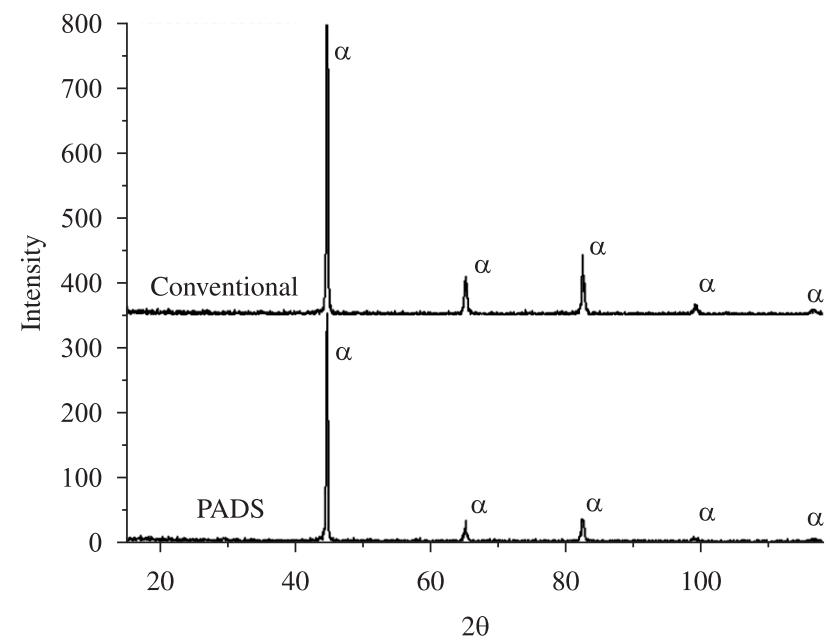

Figure 3. XRD diffraction patterns of both sintered 17-4PH stainless steels.

Table 2. Copper content after sintering with PADS and conventional technologies.

\begin{tabular}{ccc}
\hline $\mathrm{Cu}(\%$ w/o) powder & System & $\mathrm{Cu}(\%$ w/o) parts \\
\hline 4.5 & PADS & 3.0 \\
& Conventional & 4.4 \\
\hline
\end{tabular}

copper loss was observed for the parts processed in the PADS furnace. Another observation that suggests copper evaporation was the surface colour of these parts, as shown in Figure 4.

The reasons for the lower amounts of copper in the parts processed under plasma can be explained qualitatively by the vapour pressure behaviour of elemental copper. At $1330{ }^{\circ} \mathrm{C}$, the calculated vapour pressure of $\mathrm{Cu}$ is approximately 0.03 mbar, as shown in Figure 5. It is reasonable to believe that this pressure is even higher because copper in the 17-4PH stainless steel is certainly not in the elemental phase. Thus, at the current sintering temperature $\left(1330^{\circ} \mathrm{C}\right)$, the vapour pressure of copper is very close to the working pressure of the PADS furnace (1.00 mbar), which generates a high evaporation rate of copper in this system. On the other hand, the conventional vacuum furnace runs in pressures ranges of 130 mbar. Thus, the evaporation rate is reduced by 100 times in the conventional route when compared to the plasma system, enabling a successful copper level maintenance.

After explaining how copper leaves the material during sintering at very low pressures, the effects of this element on the grain growth behaviour can be clarified. First of all, it might be feasible that $\mathrm{Cu}$ atoms are placed in the material in two possible scenarios: as a substitutional atom in a solid solution or as copper precipitates along the grain boundaries. Both conditions are favourable for breaking the grain coarsening due to the following mechanisms:

- Substitutional atoms: if simply removing the copper atoms from their initial position in the crystal by evaporation, a vacancy is created. As a consequence, the vacancy diffusion rate increases, and the grain migrates easily due to the thermodynamic tendency to reduce the total grain boundary energy ${ }^{14}$.

- Copper precipitates: if placed along the grain boundaries, the second phase particles may exert a pulling force on the boundary, restricting its motion ${ }^{14}$. If these precipitates are removed, the boundary is free for coarsening.

One feasible way to prevent the copper evaporation during processing in the PADS furnaces is switching off the plasma discharge after approximately $1000{ }^{\circ} \mathrm{C}$ and increasing the pressure of the hot

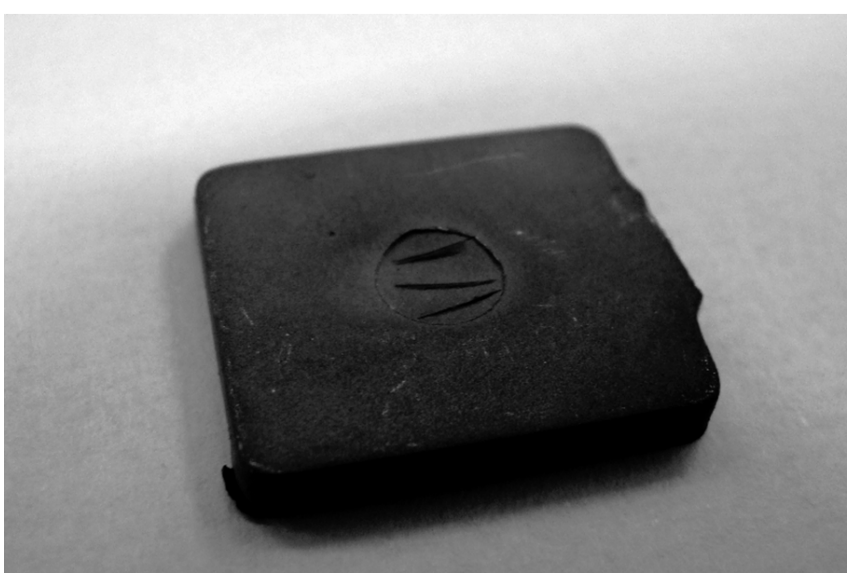

Figure 4. Coloured surface suggesting evaporation of copper during sintering at 1 mbar.

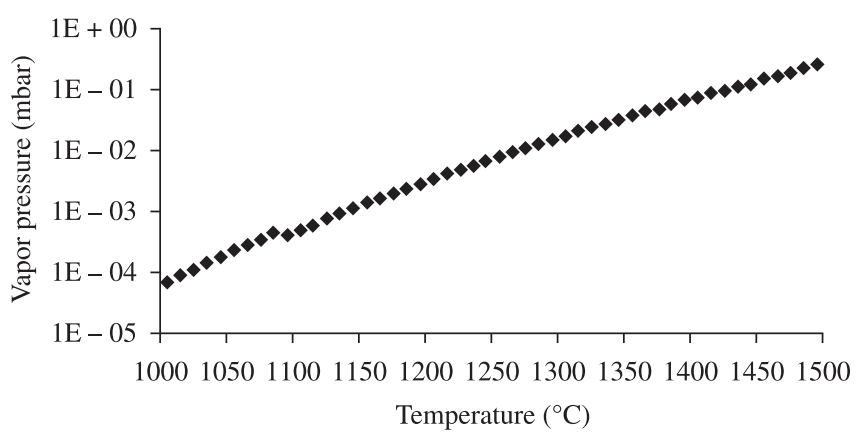

Figure 5. Vapour pressure behaviour of elemental copper at different sintering temperatures ${ }^{13}$.

zone to more than 100 mbar. At this temperature, the plasma does not have a significant effect on the parts, and the furnace can run in a plasma-free condition similar to what occurs in conventional furnaces. In other words, one might use the plasma discharge only for debinding.

\subsection{Very low carbon content}

This hypothesis is quite similar to the previous one in which the plasma removes potential substances from grain boundaries, allowing grain coarsening. However, in this case, the elimination of carbonbased constituents instead of copper-based substances is suggested. It is well known that carbides have a strong tendency to precipitate along the grain boundaries, thus acting as a barrier for grain growth.

Atomic hydrogen $(\mathrm{H})$ could have an important role in this decarburizing behaviour and consequent cleaning of grain boundaries. If the ratio of carbides is very low, the grains have fewer restrictions for coarsening.

This assumption was suggested based on the very low values of carbon found for the parts processed in the PADS furnace. Muterlle et al. ${ }^{15}$ carried out an investigation on the influence of the carbon content on microstructure of the 17-4PH using powders with carbon contents at the level of $0.03-0.06 \%$ w/o, and no discrepancy on the grain morphology was observed. By using the PADS system, the carbon content was $0.003 \%$ w/o and, thus, not comparable to those results.

\subsection{Magnetic field of the plasma discharge}

Lourenço ${ }^{16}$ observed an abnormal grain growth in unalloyed iron parts sintered under plasma in his PhD work. He suggested 
Table 3. Tensile properties of MIM 17-4PH stainless steel sintered parts in PADS and conventional vacuum furnaces at $1330^{\circ} \mathrm{C}$.

\begin{tabular}{lccc}
\hline \multicolumn{1}{c}{ Samples } & $\begin{array}{c}\text { Yield strength } \\
(\mathrm{MPa})\end{array}$ & $\begin{array}{c}\text { Ultimate tensile } \\
\text { strength }(\mathrm{MPa})\end{array}$ & $\begin{array}{c}\text { Elongation } \\
(\%)\end{array}$ \\
\hline Conventional & $769 \pm 6$ & $947 \pm 7$ & $5 \pm 1.8$ \\
PADS & $717 \pm 12$ & $882 \pm 12$ & $5 \pm 1.6$ \\
\hline
\end{tabular}

that this behaviour was a result of the combination of the magnetic field generated by the glow discharge plasma and the different magnetic susceptibility of the grains. Because the grains respond to an applied magnetic field in different ways, they should migrate at different rates and preferable directions. However, no systematic study has been carried out to understand the effects of plasma on the grain morphology, which is still an interesting point to research in depth.

\section{Tensile Tests}

The mechanical properties resulting from the tensile tests are given in Table 3. The strength values were slightly lower for the parts processed in the PADS furnace than for those obtained via conventional route, but the elongation behaviour was almost identical.

The abnormal grain growth was suggested as a feasible but not conclusive answer for this mismatch in strength. It is well known that one method for strengthening materials is changing the grain size grain boundary strengthening ${ }^{17}$. In other words, grain refinement leads to a higher content of grain boundaries, thus reducing the dislocation slippage process and strain gradients in the grains. Thus, because the parts processed in the PADS presented larger grains, they might exhibit lower values of strength as well.

Mutterle et al. ${ }^{15}$ concluded that delta ferrite caused a decrease in the tensile strength and no pronounced differences in ductility, but they did not describe the mechanisms for these tendencies.

\section{Conclusion}

The processing of 17-4PH stainless steel using the Plasma Assisted Debinding and Sintering technology led to properties similar to those obtained when the parts were processed via conventional MIM industrial routes. The advantages of the PADS system were the large reduction in processing time (10 hours of debinding and sintering) and the cleanness of the chamber after each cycle.

An interesting factor found during the processing of this stainless steel was the very low carbon content $(0.003 \%$ w/o) of the sintered parts. Although no experiment on this topic was carried out in this investigation, this low content may induce an optimized corrosion resistance.

The grain morphology was also very intricate when the samples were processed under glow discharge plasma. An abnormal grain growth was observed, and some explanations for this phenomenon were suggested. Despite the larger grains, the mechanical properties evaluated by the tensile tests were not much affected. Further experiments focusing on the thermodynamics, plasma physics and powder metallurgy are necessary to verify the explanations or possibly find new theories.

In summary, this work has demonstrated an attractive relationship between powder metallurgy and plasma technology in terms of financial topics and metallurgical advances. Certainly, the PADS system has much to contribute to achieve even better results in the metal injection moulding business.

\section{Acknowledgements}

The authors are grateful to the MIM producer Lupatech/ Steelinject and to the Brazilian agencies CAPES and CNPq for the financial support.

\section{References}

1. Klein AN, Muzart JLR, Souza AR, Fredel MC, Wendhausen PAP and Nascimento RM. Process for removal of binders from parts produced by powder injection molding. 2003. Patent US 6,579,493 B1.

2. Wendhausen PAP, Fusão D, Klein AN, Muzart JLR, Ristow Junior W and Machado R. Plasma Assisted Debinding and Sintering: Process and Equipment. In: Proceedings of the Powder Metallurgy World Congress \& Exhibition; 2004; Vienna, Austria. Vienna; 2004 p. 137-142.

3. Machado R, Ristow Junior W, Alba PR, Klein AN, Wendhausen PAP and Fusão D. Plasma Assisted Debinding and Sintering (PADS): Metal Injection Molding Application. Materials Science Forum. 2006; 530-531:224-229.

4. Machado R, Ristow Junior W, Klein AN, Muzart JLR, Fredel MC, Wendhausen PAP et al. Industrial plasma reactor for plasma assisted thermal debinding of powder injection molded parts. 2010. Patent US 7,718,919 B2

5. Joens $\mathrm{C}$ and Benerjee S. Plasma paradigm test for MIM sintering boost. Metal Powder Report. 2009; 64(1):31-33. http://dx.doi.org/10.1016/ S0026-0657(08)70182-6

6. Zhang $\mathrm{H}$ and German RM. Powder Injection molding of 17-4PH Stainless Steel. In: Proceedings of Powder Injection Molding Symposium; 1992; San Francisco. MPIF; 1992. p. 219

7. Jones R and Randle V. Sensitisation behavior of grain boundary engineered austenitic stainless steel. Materials Science and Engineering A. 2010; 527:4275-4280. http://dx.doi.org/10.1016/j.msea.2010.03.058

8. Wu Y, German RM, Blaine D, Marx B and Schlaefer C. Effects of residual carbon content on sintering shrinkage, microstructure and mechanical properties of injection molded 17-4 PH stainless steel. Journal of Materials Science. 2002; 37:3573-3583. http://dx.doi. org/10.1023/A:1016532418920

9. Sago JA, Wilson MD, Broadley MW, Eckert JK and White RJ. The effects of sintering cycle and alloy design on the microstructure and mechanical properties of MIM 17-4PH stainless steel. In: Proceedings of Powder Metallurgy and Particulate Materials; 2008; Washington. MPIF; 2008. part 4.

10. Wu Y, Blaine D, Marx B, Schlaefer C and German RM. Sintering densification and microstructural evolution of injection molding grade 17-4 PH stainless steel powder. Metallurgical and Materials Transactions A. 2002; 33(A):2185-2194.

11. Dutra GB, Mulser M and Petzoldt F. Thermodynamic Simulation of 316L and 17-4PH Stainless steels using different Process Conditions for Two Components Metal Injection Moulding (2C-MIM). In: Proceeding of the Powder Metallurgy World Congress \& Exhibition; 2009; Copenhagen, Denmark. Copenhagen; 2009. p. 93-98.

12. Swanson HE, Gilfrich NT and Ugrinic GM. Standard X-ray diffraction powder patterns. National Bureu Standard; 1955. Circulation, n. 539, v. 4.

13. Gale WF and Totemeier TC. Smithells metals reference book. 8th ed. Elsevier Butterworth-Heinemann; 2004.

14. Porter DA and Easterling KE. Phase transformations in metals and alloys. 2th ed. Taylor and Francis Group; 2004.

15. Lourenço JM. Evolução microestrutural de ferro puro e ligas ferrosas sinterizadas por plasma. [Tese]. Florianópolis: Federal University of Santa Catarina; 2004.

16. Mutterle PV, Zendron M, Perina M, Bardini R and Molinari A. Influence of carbon content on microstructure and tensile properties of the 17-4PH stainless steel produced by MIM. Powder Injection Moulding International. 2008; 2(4).

17. Dieter GE. Mechanical Metallurgy. SI Metric Edition. McGraw-Hill; 1988. 188 p. Series in Materials Science and Engineering. 